\title{
Research on Autonomous Learning of Network Teaching Platform
}

\author{
Sheng Juan \\ Northeastern University at Qinhuangdao \\ QinHuangdao, China \\ ling_dingdang@hotmail.com
}

\begin{abstract}
Abtract-Application of network teaching platform can provide abundant resources for students' learning; it can break the limitation of time and space in traditional class teaching system. But in actual use, there have lots of shortages, such as low utilization rate, delayed feedback; this situation influences the effect of the network platform use. This paper will analysis the construction of existing network teaching platform, studies on network teaching platform of Autonomy guide, teaching interaction and so on, and improve the strategy to build it.
\end{abstract}

Keywords-Network teaching Platform, autonomy guide, teaching interaction

\section{I. .INTRODUCTION}

With the rapid development of the network technology and application, the traditional learning mode of classroom teaching has started to change, More and more network technology is introduced to the teaching, Many universities are constructing the Network Teaching Platform(NTP),on the one hand , the application of network teaching platform can provide more abundant resources for students' study, on the other hand it can break the limitation of time and space in traditional class teaching system and bring more convenience. But In the practical application process, because most students are used to rely on the teacher's arrangement to study before they entered the university. They are usually lack of autonomous learning ability, they will feel the difficult to adapt to the use of the network teaching platform. Although the network teaching platform has significant advantages, but its building form and composing strategy decides practicality and effectiveness of the platform in the very great degree. This paper will analysis the construction of existing network teaching platform, studies on network teaching platform of Autonomy guide, teaching interaction and so on, and improve the strategy to build it.

\section{THE DEVELOPMENT OF THE NETWORK TEACHING PLATFORM}

Research and development of network teaching platform has basically gone through three generations of products [1][2]. The first generation is the e-book mode, its character is transforming the traditional textbook to electronic documents, and matching with a variety of multimedia technologies (such as graphics, images, sounds, animations, and so on), This way converts the static information to dynamic information, This kind of external stimuli to learners enhances the learner's learning interest and teaching effectiveness. The Second generation is electronic courseware mode; it promotes a class in the content organization, it adds the experience of preparing for class, teaching experiences. However, these two types of products are based on the traditional teaching mode, the reality which teachers are as the main body of the teaching mode has not changed. The third generation is network teaching platform, Network teaching platform tries to integrate some necessary function such as the teaching content, students learning feedback, as well as interaction between the teachers and students etc. Network teaching platform typically includes the following sections: (1) curriculum design, including interface perception, learning tools, assessment tools etc; (2) course management, including establishing and maintaining online courses, users log in or log out, students' selfevaluation, homework submission, and so on.(3) By using computer network and multimedia technology, more learners can interact, collaborate and exchange ideas for a same learning content by virtual community, online BBS and voice chat rooms etc. Network teaching platform and participants form are generally shown in the following figure 1:

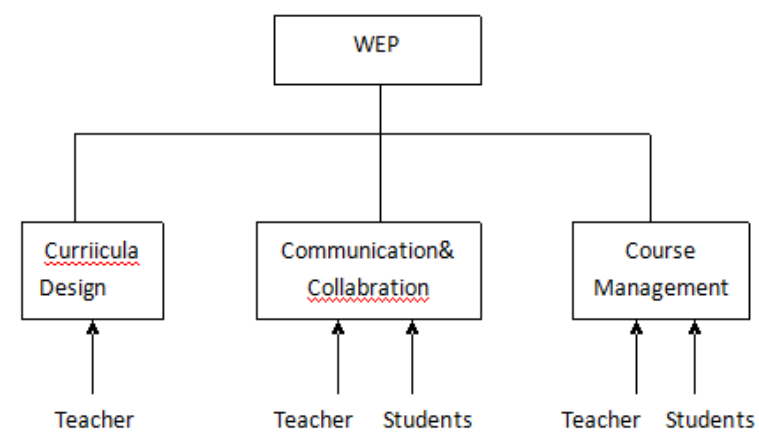

Figure 1. Network teaching platform and participants form

\section{DEFINITION AND CHARACTERISTICS OF NETWORK TEACHING}

Network teaching platform can realize its superiority only if it reflects the characteristics of the network teaching. Network teaching is a kind of modern teaching process, which is completed to realize multidirectional interaction and resource sharing in computer network environment through teachers, students, media, and other media. The basic characteristic of the network teaching is[3][4]:

(1) The core and foundation in Network teaching is computer network and Multimedia technology, besides that, 
using a variety of techniques, focusing highly on modern teaching technology's integration.

(2) Teachers, students, the media are basic elements of interaction, there are multilateral, more interaction between these three. Teaching resources achieve sharing. Group teaching, individual teaching, and self-learning become an organic whole.

(3) Students are as active entities, students ' autonomous learning and individual learning are emphasized.

(4) By breaking the traditional teaching patterns in time and space, limitations of information and other aspects are adapt to the demand of "learning community".

(5)By introducing the theory of cognitive structure, autonomous learning, humanist builds a "studentsorientation " learning environment.

\section{THE APPLICATION OF NETWORK TEACHING} PLATFORM

From the network teaching platform structure we can see it avoids the traditional teaching teachers' one-way communication faults because students can assess learning and communicate with each other through the learning system, But because it is based on the traditional teaching, so network platform in practical application is still difficult to achieve ideal application state, the faults are mainly in five aspects [5][6]:

(1) Not Outstanding of Network Teaching Platform Features

The characteristics of network education determines the main body of teaching construction should be students, so the orientation of network teaching platform should be building " learning-centered “ environment, but existing network platform is still the aggregation of resources, it cannot highlight the autonomy of guidance and supervision of the learning process for network teaching platform.

(2) Low resource utilization of network teaching platform

Existing network teaching platform, usually integrates more module and more resources, But the system is usually lack of retrieval function, it is difficult to find the information learners need actually, a large number of resources cannot be effectively use. Platform in the use of different subjects appears a large number of redundant constructions; this wastes a lot of human and financial resource.

(3) The lack of personalized learning guide

While the rich learning resources of network teaching platform, but their function often lacks analysis of the learner's personality, and is also very passive for the learners ' understanding, the guide is obvious inadequate for students ' autonomous learning, and that is precisely what the key elements of network teaching platform.

(4) Insufficient feedback for platform effect

How well does Network platform use? It should be judged by the resource download, test system practice frequency or teacher resources update situation, the platform is usually lack of related data, so platform effect is lack of sufficient feedback.

\section{(5) Insufficient learning model}

In the network teaching platform we often have a lot of excellent homework and design work, but the design of the platform is usually limited to teachers and students' twoway communication, instead of multidimensional communication, which make some outstanding works can't be demonstration.

\section{NETWORK TEACHING PLATFORM IMPROVEMENT STRATEGY}

\section{Introducing cloud computing technology [7]}

Applying the cloud computing technology in the network teaching can use and integrate the existing hardware resources, Because cloud computing scalability is very strong, the school can make existing hardware resources and teaching resources join a "cloud", The way can avoid repetitive construction of teaching platform in different professional and subject between, it also can realize the real meaning of the sharing of resources, reduce the user's trouble who need register information in different platform.

(2) Adding the autonomous learning element and introducing point system [8]

The characteristics of the network teaching platform are based on students as the main body activity, emphasizing students' initiative in learning and individualized learning. But the actual situation of platform's application may not be the case; they will stop the use of the platform after accomplishing the task or test which is arranged by their teacher. The lack of effective supervision and incentive mechanism leads to lack of students' learning autonomy. In order to stimulate students ' knowledge driven, the platform can introduce point system which is widely used in commercial field. At the same time, it can make full use of database technology, and set up all kinds of integral items (such as homework integral, the problem submit integral, the question answer integral, resource integration, resource download upload integral, etc.) and establish a record of learning. This method can be multidimensional quantization for students' learning; students can see their learning dynamic change through the network platform and increasing learning power.

(3) Establishing a multilateral sharing and increasing the display function

The teacher can give a score to homework which students submit to the network platform; students can also look up score through the platform, this evaluation method is static, scores of students is just only a score, it has no effect on other students. The teacher can reward creative integral to outstanding work, the work which obtained the creative integral can be placed in display module, this way can turn teachers' and students' two-way communication into students and student's multidirectional communication, static score evaluation changes into dynamic thinking development.

(4) Enriching platform interaction level 
Good interactive ability is an important measure of network teaching platform effect characteristics. Teaching interaction often includes operating interaction, information interaction, and concept interaction. Network operating platform need more enrich the three interactive levels.

\section{CONCLUSION}

In a word, the network teaching platform should fully embody its rich resources, strong interactivity, autonomous learning features, Use the humanistic ideas and constructivism theory to build "students-orientation " autonomous learning platform, Cultivate learners innovation spirit and practice ability, Make them in the network rich environment on the teacher's guidance, With independent learning as the center, with a variety of media teaching resources and interactive methods assisted learning, learners can make self-motivation by the study integral, check up learning effect by a learning record, so as to achieve better for subsequent autonomous learning cultivate solid ability. Hopefully, these improvements can make better learning effect and cultivate solid autonomous ability for subsequent learning.

\section{REFERENCES}

[1] LI Fang. On A Teaching Mode of Network. Journal of Guangdong Insti tute of Public Administration, Vol. 13No. 3, Jun. 2001.

[2] JianliangLi, Yang hang. Research on Construction of Web-based Educa tion. 2010 Third International Conference on Education Technology and $\mathrm{Tr}$ aining (ETT), china, 2010.

[3] Mingli Liu, Dan Mu. The Research Interactive Teaching Mode Based o n Network. Proceedings of the Conference on Web Based Business Manag ement, china, 2010.

[4]Xuhui Tang, Xue Li. Concerning the network teaching mode. Journal of Higher Correspondence Education (Philosophy and Social Sciences), Vol. 20 No. 1, January2007.

[5]Xiaoqiang Han. A Brief discussion network education platform problem s and improvement strategy. Technology economic market, Vol.7, 2009.

[6]Wei Xiao jun. Network Education Platform Development at Home and Abroad Present Situation Analysis Research. Theory Research, Vol.1, 2012 [7] Fucheng Wang, Zhishui Zhong. Cloud Computing Based Network Teac hing Platform Design. Journal of Tong Ling University, Vol.6, 2011

[8] Zhiqun WANG. Reform and Practice of Game Points System in C Lang uage Program Design. The 11th National Annual Symposium on Industrial Technology of Economic Management Institutions, china, 2012 